\title{
The Influence of Different Doses of Oxytetracycline on Some Hematological Parameters in Broilers
}

\author{
S. TRÎNCA ${ }^{1}$, L. OGNEAN ${ }^{* 1}$, Viorica CHIURCIU ${ }^{3}$, C. CHIURCIU ${ }^{3}$, Alexandra ARION ${ }^{1}$, \\ Ioana DUMITRU ${ }^{2}$ \\ ${ }^{1}$ Department of Physiology, University of Agricultural Science and Veterinary Medicine Cluj-Napoca \\ ${ }^{2}$ Department of Anatomy, University of Agricultural Science and Veterinary Medicine Cluj-Napoca \\ ${ }^{3}$ Romvac company \\ Corresponding author: lognean@yahoo.com
}

Bulletin UASVM Veterinary Medicine 72(1) / 2015,

Print ISSN 1843-5270; Electronic ISSN 1843-5378

DOI:10.15835/buasvmcn-vm: 9352

\begin{abstract}
Background: Antibiotic use as curative, preventive and as growth promoter is often common practice in broiler farming. The problem of residues in the products obtained, often sparked debates among farmers who recognize the benefits of antibiotics and consumers who fear risks of using such products. This research focuses on evaluating the effects of an oxytetracycline product overdose on hematological parameters of broilers in correlation with symptomatic manifestation.

Materials and methods: Two experimental broiler groups $(\mathrm{n}=11)$ were subjected to treatment 8 and 16 $\mathrm{X}$ therapeutic dose over a period of 3 days and a control group $(n=12)$ were kept in identical conditions for housing and feeding. Blood samples were collected from the birds 12 hours after the last administration (posttreatment) in case of the experimental groups respectively at the end of the experiment from the control and the usual hematological parameters were determined. The recorded data was statistically processed and interpreted.

Results: Individual data revealed more or less important oscillations in the investigated parameters. Statistical analysis showed no significant changes except for hemoglobin $(p=0.0038)$ and MCHC $(p=0.0025)$ respectively the total number of leukocytes $(p=0.0022)$ and lymphocyte subpopulation $(p=0.0440)$.

Conclusions: Investigations undertaken to assess the effects of overdose with oxytetracycline based product showed significant changes in hemoglobin concentration and MCHC respectively. The total number of leukocytes and lymphocyte subpopulation level, the changes found mainly in the group treated with the highest dose can be attributed to a possible drug imunosupression.
\end{abstract}

Keywords: broiler chicken, doses, , hematology, oral administration, oxytetracycline.

\section{INTRODUCTION}

Excessive antibiotic use in broiler farming is an important issue in terms of consumer health. Antibiotic use as curative, preventive and as growth promoter is often common practice in intensive broiler farming. The problem of residues in products obtained from these birds often sparked heated debates among poultry farmers who recognize the benefits of antibiotics and consumers who fear risks of using such products.

Al-Mayah et al. (2005) and Ognean (2011) mention that broiler exposed to therapeutic and double doses of antibiotic based medical products have no significant impact on the hematological parameters of broilers. This fact associated to the delayed manifestation of pathological or toxic symptoms in bird species raises concerns about the levels of antibiotics given in current farming practices.

This practice of antibiotic use as growth prompters and preventives agents made them common use in the last decade because of their noticeable results in the performance of the animals raised using these methods. 
Determining the levels of antibiotic residues is a costly procedure and in case of broilers is performed on meat samples, usually randomized, from sacrifices charges. Finding such residues in meat means first of all the fact that the meant in improper for human consumption therefore has to be confiscated and denaturized. This leads to huge economic loss for the producers.

The aim of our research is to investigate the hematological effects of an oxytetracycline based product in broilers in order to establish some alteration patterns in them that may indicate over dosage without resorting to performing residue dosage.

Finding hematological signs in live animals is an opportunity to determine accidental over dosage using less expensive hematological tests and providing the farmers a way to avoid losses through confiscation by prolonging the wait period in such cases.

\section{MATERIALS AND METHODS}

Two experimental groups $(\mathrm{n}=11)$ of clinically healthy 17 day old broilers (Ross 308 line) were subjected to treatment with an oxytetracycline chloral hydrate based product (Galiprotect), and one was kept in identical feeding and housing condition as control $(n=12)$.

The two experimental groups were given oral overdoses of 8 and respectively 16 times the recommended dosage of the product over a period of 3 consecutive days.

Blood samples were obtained via basilar vein flebocentesys in EDTA collection tubes posttreatment from the birds in the experimental groups.

Researched parameters included: complete blood count or CBC (number of erythrocytes and leukocyte), hematocrit (Ht), hemoglobin ( $\mathrm{Hb})$, mean erythrocyte constants (MCV, MCH and MCHC) and differential leukocyte counts $(\mathrm{H}, \mathrm{E}, \mathrm{B}, \mathrm{L}, \mathrm{M})$. CBC was achieved with a hemocytometic method, $\mathrm{Hb}$ concentration thru spectrophotometry and the PCV using a micro hematocrit. Mean erythrocyte constants were calculated from these results, the differential leukocyte counts were done on DiaQiuck stained blood smears.

Statistically analysis was made with specialized applications (InGraphPad, OriginPro) using the Tukey statistical test.

\section{RESULTS AND DISCUSSION}

Results showed a mean total number of erythrocytes of $2.46 \pm 0.45 \mathrm{~T} / \mathrm{l}$ for the control group, $2.62 \pm 1.03$ for the group receiving an $8 \mathrm{X}$ overdose and $2.31 \pm 0.48$ for the group receiving a 16X overdose. Statistical analysis did not show significant differences between the 3 investigated groups (Fig. 1).

Hemoglobin showed a dose dependent decrease from a mean value of $7.92 \pm 0.97 \mathrm{~g} / \mathrm{dl}$ in the control group to $7.10 \pm 1.12 \mathrm{~g} / \mathrm{dl}$ in the group receiving an $8 X$ overdose and to $6.40 \pm 0.84 \mathrm{~g} / \mathrm{dl}$ in the group receiving a $16 \mathrm{X}$ overdose. Analyzed data showed significant differences between the groups $(p=0.0038)$ indicating that the treatment with the oxytetracycline influences this parameter in a decreasing manner (Fig. 1).

Packed cell volume ranged between a maximum of $39.96 \pm 8.56 \%$ for the group receiving a $16 \mathrm{X}$ overdose and $33.87 \pm 5.83 \%$ for the controls. Although this parameter showed an increase, this was not of statistical value. The mean erythrocyte constants showed a particular development with statistically significant changes found only in MCHC. MCV values ranged between a maximum of $178.27 \pm 8.36 \mathrm{fl}$, in the group receiving a $16 \mathrm{X}$

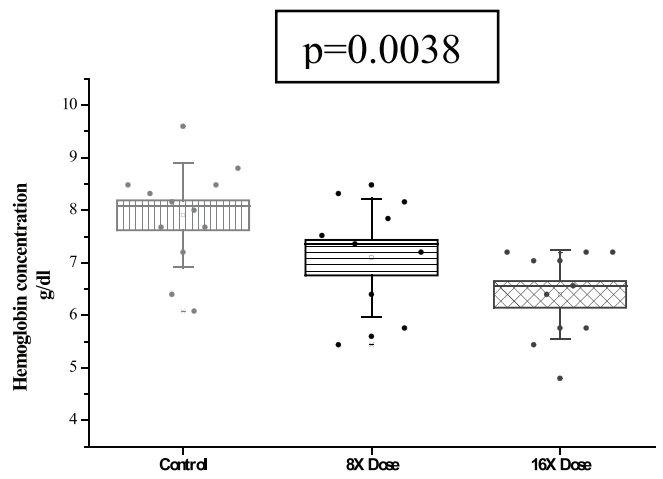

Fig. 1. Erythrocytes number of and hemoglobin changes of the 3 groups. 
overdose and a minimum of $153.25 \pm 43.47 \mathrm{fl}$ from the group receiving an $8 \mathrm{X}$ overdose.

MCH oscillated in the interval of $34.09 \pm 10.01$ $29.50 \pm 8.29 \mathrm{pg}$ with no statistically significant differences between the groups (Fig. 2). MCHC showed a decrease due to the hemoglobin that also decreased, with a statistically significant differences $(\mathrm{p}=0.0025)$ (Fig.2).

Total numbers of leukocytes were observed to be on the rise in the experimental groups (Fig. 3). Mean values for the control group were of $13.66 \pm 7.29 \mathrm{G} / \mathrm{l}, 24.95 \pm 9.55 \mathrm{G} / \mathrm{l}$ for the group receiving an $8 \mathrm{X}$ overdose and $22.95 \pm 4.90 \mathrm{G} / \mathrm{l}$ for the group receiving a $16 \mathrm{X}$ overdose. Statistical analysis showed significant differences between the 3 groups ( $p=0.0022$ ) (Fig. 3). This none dosedependent leukocytosis can be attributed to the individuals found in that group, however further research is needed.

Heterophiles showed a mean value of $54.41 \pm 7.93 \%$ in the control group, $54.55 \pm 9.82 \%$ in the group receiving an $8 \mathrm{X}$ overdose and $61.55 \pm 5.88$ $\%$ in the group receiving a 16X overdose (Fig. 4).

No statistically significant differences were found between the investigated groups. The increase can be explained by the inhibition of the heterophil chemotactism, which sequestrates

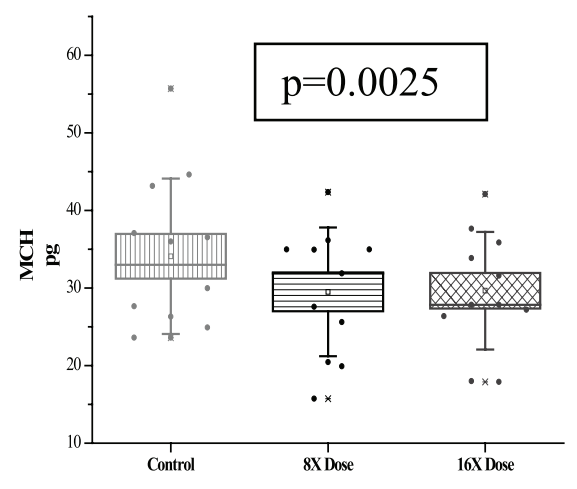

them in the blood stream increasing their number (Majeski and Alexander, 1977).

Eosinophil subpopulation had a mean value of $3.64 \pm 2.76 \%$ in the group receiving a $16 \mathrm{X}$ overdose and $4.45 \pm 3.14 \%$ in the group receiving an $8 \mathrm{X}$ overdose. The basophiles were rarely found on the blood smears, with values of 0.00 in all the investigated samples.

Lymphocyte levels were of $31.92 \pm 9.62 \%$ in the control group, $25.64 \pm 12.46 \%$ in the group receiving an $8 X$ overdose and $21.36 \pm 5.90$ in the group receiving 16X overdose (Fig. 4). Analyzed data showed significant differences between the 3 groups $(\mathrm{p}=0.0440)$.

The dose-dependent decrease might be attributed to the $\mathrm{AD}_{3} \mathrm{E}$ vitamin complex in the product that is known to induce lymphopenia as a side effect (Fiț et al., 2011).

Monocytes were at a mean level of $8.83 \pm 5.50 \%$ in the control group, $15.36 \pm 7.24 \%$ in the group receiving an $8 X$ overdose and $21.36 \pm 5.90 \%$ in the group receiving a $16 \mathrm{X}$ overdose (Fig. 4).

Statistical analysis did not show any significant differences. Overall, the hematological parameters showed a dose dependent decrease in hemoglobin, MCHC and of lymphocyte percentage

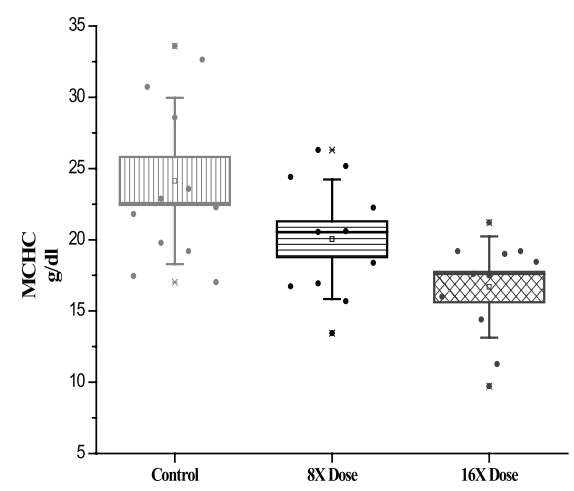

Fig. 2. $\mathrm{MCH}$ and $\mathrm{MCHC}$ in the 3 investigated groups.
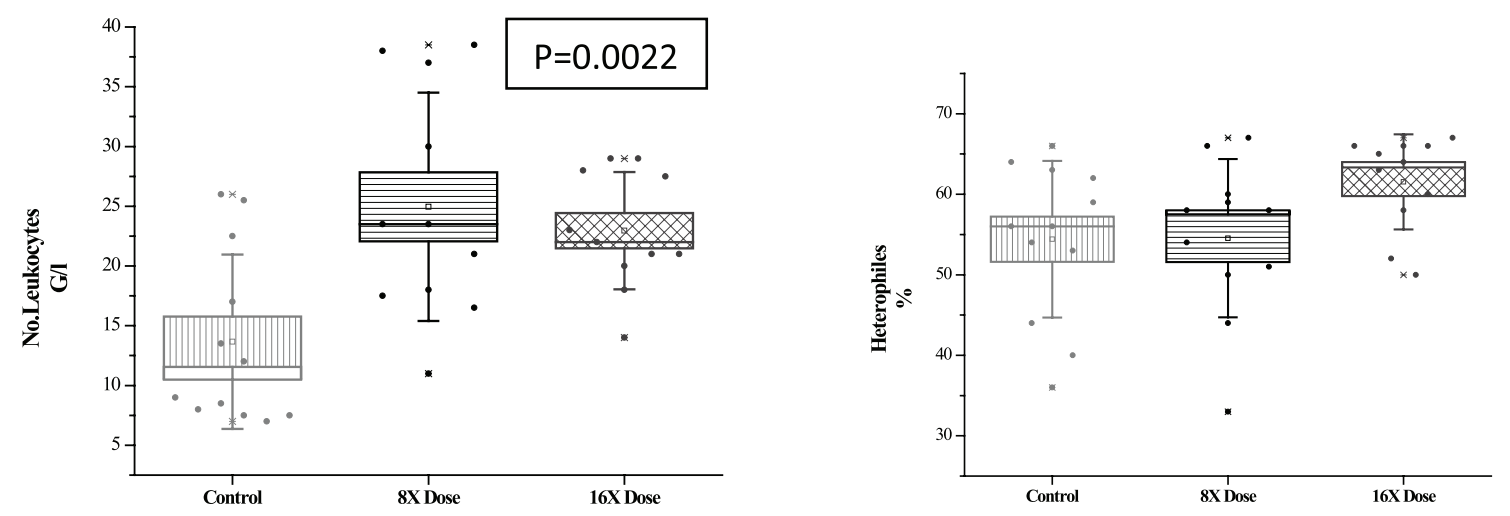

Fig. 3. Number of leukocytes and heterophile percentages within the 3 groups. 

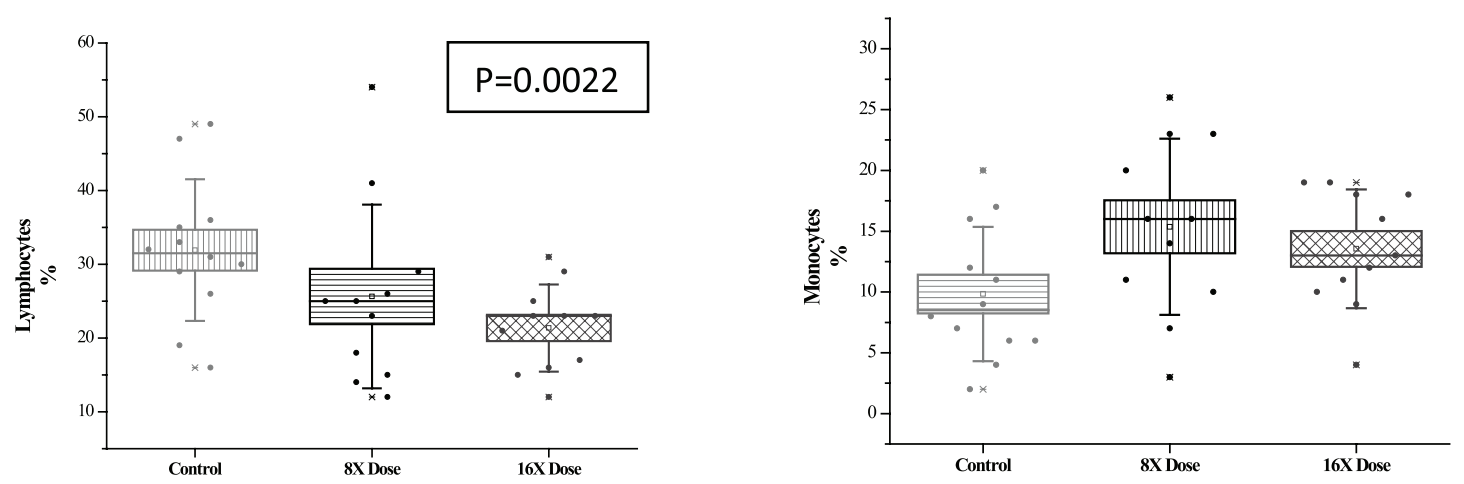

Fig. 4. Number of leukocytes and heterophile percentages within the 3 groups.

together with a non-dose dependent increase in leukocyte number.

This research adds to the ones made by $\mathrm{Al}$ Mayah et al. (2005), Ognean et al. (2011) and Turcu et al. (2011), who researched antibiotic products on hematological parameters in broiler chickens by taking it further and overdosing them.

Our data shows that a decreased in hemoglobin, MCHC and lymphopenia, with mild leukocytosis can indicate an oxytetracycline overdose.

Although some of the significant differences may be attributed to the $\mathrm{AD}_{3} \mathrm{E}$ vitamin complex, since these complexes are present in most medicinal products intended for veterinary use, especially in poultry their side-effects should also be taken into account.

The changes found in the hematological profile may represent a possible warning sign of overdose in live animals, signs that can be detected in routine hematological investigations (Chung and wood, 1970). Although more research in this field is required, the obtained results exhibit that hematological investigations are early (intra vitam) detection methods for medicinal product over dosage.

The cited literature shows lack of information regarding the influence of drugs on the hematological values in meat type chickens raised in an intensive system, an aspect that justifies the screening of the hematological and biochemical profiles. These types of tests can also be useful in the concern of an accidental drug overdose.

\section{CONCLUSION}

1. Although less expensive and less specific than residuedeterminations, hematologicalinvestigations offer an early (intra vitam) warning sign of over dosage of the aforementioned veterinary medicinal product;

2. Regarding the erythrocyte parameters, a statistically significant dose-dependent decrease in hemoglobin concentration $(p=0.0038)$ associated with a similar development in MCHC $(\mathrm{p}=0.0025)$ were found;

3. Leukocyte parameters showed a non-dose dependent increase in the total number of white blood cells associated with a dose-dependent lymphophenia;

4. The detected lymphopenia associated with overdose of the tested products must attribute and their content vitamin AD3E complex;

5. Eventhough further research is needed in this filed, routine hematological investigations can offer a warning signs to broiler farmers of accidental drug over dosage. This way they will be able to take an adequate measures to ensure the lack of antibiotic residues in the meat and therefore the safety of their product.

\section{REFERENCES}

1. Al-Mayah AS, JA AL-Ahmed (2005). Influence of antibiotics treatment on hematological aspect in chickens. International Journal of Poultry Science 4(5):323-325.

2. Chung J, Wood JL (1970). Oxidation of thiocyanate to cyanide catalyzed by hemoglobin. Journal of Biological Chemistry 246(3):555-560.

3. Fiț N, Chirila F, Nadas G, Răpuntean S, Ognean L, Trîncă S, Cuc(Bouari) C (2012). Haematological biochemical and microbiological studies at pigeons treated with a product based on metronidazole, oxytetracycline, furazolidone and bismuth sub-nitrate. Bulletin UASVM Veterinary Medicine 69(1-2):120-127.

4. MajeskiJA, Alexander JW (1977). Evaluation of tetracycline in the neutrophil chemotactic response. The Journal of Laboratory and Clinical Medicine 90(2): 59-265.

5. Ognean L, Chiurciu V, Cernea C, Trîncă S, Oroian R (2011). The evaluation of therapeutic doses of erythromycin on the main hematological parameters of broiler chickens. Bulletin UASVM Veterinary Medicine 68(1):277-283.

6. Turcu D, Oporanu M, Grigorescu P, Roman M (2011). Studii privind parametri hematologici la pui broiler tratați cu Amoxidem 50\%. Medicamentul Veterinar/Veterinary Drug 5(1). 